ORIGINAL ARTICLE

\title{
Cumulative exposure to dust and gases as determinants of lung function decline in tunnel construction workers
}

\author{
B Bakke, B Ulvestad, P Stewart, W Eduard
}

Occup Environ Med 2004;61:262-269. doi: 10.1136/oem.2003.008409

See end of article for authors' affiliations ....................

Correspondence to: Dr B Bakke, National Institute of Occupational Health, PO Box 8149 Dep. $\mathrm{N}-0033$ Oslo, Norway; berit.bakke@stami.no

Accepted 21 July 2003

\begin{abstract}
Aims: To study the relation between lung function decrease and cumulative exposure to dust and gases in tunnel construction workers.

Methods: A total of 651 male construction workers (drill and blast workers, tunnel concrete workers, shotcreting operators, and tunnel boring machine workers) were followed up by spirometric measurements in 1989-2002 for an average of six years. Outdoor concrete workers, foremen, and engineers served as a low exposed referent population.

Results: The between worker component of variability was considerably reduced within the job groups compared to the whole population, suggesting that the workers within job groups had similar exposure levels. The annual decrease in $\mathrm{FEV}_{1}$ in low-exposed non-smoking workers was $21 \mathrm{ml}$ and $24 \mathrm{ml}$ in lowexposed ever smokers. The annual decrease in $\mathrm{FEV}_{1}$ in tunnel construction workers was 20-31 ml higher than the low exposed workers depending on job group for both non-smokers and ever smokers. After adjustment for age and observation time, cumulative exposure to nitrogen dioxide showed the strongest association with a decrease in $\mathrm{FEV}_{1}$ in both non-smokers, and ever smokers.

Conclusion: Cumulative exposure to nitrogen dioxide appeared to be a major risk factor for lung function decreases in these tunnel construction workers, although other agents may have contributed to the observed effect. Contact with blasting fumes should be avoided, diesel exhaust emissions should be reduced, and respiratory devices should be used to protect workers against dust and nitrogen dioxide exposure.
\end{abstract}

nformation on the occurrence of respiratory disease among tunnel construction workers is limited. In a cross-sectional study of tunnel workers in $1991(\mathrm{n}=417)$ we found an increased risk of obstructive pulmonary disease. ${ }^{1}$ A small population of non-smoking tunnel workers with no previous tunnel experience $(n=55)$ was then followed for one year, and signs of upper and lower airway inflammation were observed. ${ }^{2}$ We also found a temporary decline in lung function in another group of tunnel workers $(n=58)$ who used a particular type of explosive. ${ }^{3}$ Agents such as nitrogen dioxide, $\alpha$-quartz, and oil mist from drilling, blasting, and diesel exhaust are common air pollutants in underground construction, and several of these agents are known to cause respiratory disease. ${ }^{4-7}$ It is not clear, however, which agents are most important.

In 1999 we reexamined the population studied crosssectionally in $1991(\mathrm{n}=345) .{ }^{8}$ A large exposure survey was carried out to estimate personal exposure levels to several chemical agents. ${ }^{9}{ }^{10}$ In this follow up study we found that tunnel workers were at increased risk of obstructive pulmonary disease and that cumulative exposure to respirable dust and $\alpha$-quartz appeared to be the most important risk factors. High correlations of exposure to several agents limited the possibility to discriminate between these agents, however.

The present study is an extension of the work of Ulvestad and colleagues. ${ }^{8}$ It includes all workers who received medical examinations as a part of routine health check ups in one Norwegian construction company. The first objective of this study was to confirm the previous findings of a relation between cumulative exposure to respirable dust and $\alpha$-quartz and lung function changes in other tunnel workers not previously studied. The second objective was to investigate whether exposures other than respirable dust and $\alpha$-quartz were associated with lung function changes. ${ }^{8}$

\section{METHODS}

Job descriptions

Tunnel work follows a sequence of drilling, blasting, transporting the broken rock out of the tunnel, spraying of wet concrete on the tunnel walls, installation and maintenance of ventilation ducts, cables, and pipes, and iron and carpentry work are performed. There were four groups of workers that mainly worked in tunnels, hereafter called tunnel workers: drill and blast workers, tunnel concrete workers, shotcreting operators, and tunnel boring machine (TBM) workers. Three low exposed job groups served as a referent population: outdoor concrete workers, foremen (perform inspection work inside the tunnels), and engineers (white collar employees). In general, tunnel construction workers work 1550 hours throughout a year, whereas outdoor concrete workers, foremen, and engineers work 1650 hours. Other details of tunnel construction work are described elsewhere. ${ }^{9}$

\section{Study design and study population}

The study population consisted of male workers employed in one of Norway's major construction companies. All employees participated in the health check ups, which mainly were carried out at the construction sites. Included in the check ups were spirometric measurements. All tunnel construction workers, outdoor concrete workers, foremen, and engineers who had more than one lung function measurement between 1 January 1989 and 31 June 2002 were included in the study;

Abbreviations: $A M$, arithmetic mean; $F V_{1}$, forced expiratory volume in 1 second; FVC, forced vital capacity; GSD, geometric standard deviation; REML, restricted maximum likelihood; TBM, tunnel boring machine; VOC, volatile organic chemical 
Main messages

- Cumulative exposure to nitrogen dioxide appears to be a major risk factor for lung function decrease in tunnel construction workers.

- Exposure to nitrogen dioxide from blasting and diesel powered equipment should be reduced.

- Construction companies that perform routine health check ups of their workers should use the data to obtain information on the occurrence of respiratory disease among tunnel construction workers and other workers.

there were a total of 663 workers. Twelve workers were excluded from the cohort: three due to spirometric measurement errors and nine because it was impossible to determine whether they had worked in tunnels. Thus, the study population comprised 651 workers. The company records provided the following information on each subject: name, social security number, job title, total number of hours on sick leave, weight, age, and smoking status.

Each worker was administered a questionnaire as part of the regular company check up. Smoking status was determined by the questions: Do you smoke? (yes/no); If yes, how much? $(0,<11 \mathrm{cig} / \mathrm{day}, 11-20 \mathrm{cig} / \mathrm{day}$, or $>20 \mathrm{cig} /$ day). The company physician and a former long term tunnel worker independently verified the job titles of the study population based on their own knowledge of the workers. They also estimated the average time that engineers and foremen spent in tunnels. Foremen were assigned to $0 \%$, $10 \%$, or $20 \%$ of their total work hours, whereas engineers were assigned to $0 \%$ or $10 \%$. Fifteen subjects changed job titles based on this evaluation.

The study was approved by the National Data Inspectorate and the Regional Medical Board of Ethics.

\section{Exposure assessment}

Details of the exposure assessment have been given elsewhere, ${ }^{9}$ and only a brief description is given here.

\section{Sampling strategy}

Sixteen tunnel construction sites were visited; personal exposure measurements of dust and gas exposure were performed on a random sample of workers from each job group for at least two days, excluding engineers and foremen. The work shift was 10 hours with two breaks of 30 minutes each. The sampling time was limited to 5-8 hours, however, because of the limited battery capacity of the sampling equipment in the dusty environment. The sampling time was considered representative of the entire work shift because the sampling periods were selected randomly within a shift and tasks were often repeated on the same day.

\section{Calculations of cumulative exposures}

Tunneling technology and outdoor concrete construction technology in Norway have not changed substantially since 1980. In addition, there were no regulations on emissions from underground construction machines in Norway until 2001. ${ }^{11}$ Temporary differences in quartz exposures may have occurred due to differences in geology across the sites. However, as the tunnel construction sites were located across Norway, no long term differences in quartz exposure were expected. The exposure measurements covered 33\% of all construction projects carried out by the company during the study period. Therefore it was assumed that the average exposure levels within the job groups were adequate estimates of the long term exposure to $\alpha$-quartz over the
Policy implications

- Steps must be taken to prevent excess respiratory morbidity among tunnel construction workers, which should include the reduction of exposures to diesel exhaust and blasting fumes (especially nitrogen dioxide), as well as dusts. A better control of exposures could be achieved by exchanging diesel powered equipment with electrically powered equipment, improving the ventilation system, and using closed and ventilated cabs.

period of study, except for shotcreting operators. New shotcreting rigs with closed cabins were introduced to the Norwegian market in 1998, but measurements on these rigs were not included in the calculation of cumulative exposure for the shotcreting operators, because the use of these rigs during the study period was limited.

Cumulative exposure of each agent (table 1) was calculated for each worker of the cohort by multiplying the time spent in a job group by the arithmetic mean (AM) exposure for that job group. ${ }^{12}$ The calculations were based on a normal work year of 1550 hours/year for tunnel workers and 1650 hours/ year for the others. TBM workers were assigned carbon monoxide levels of $2 \mathrm{ppm}$, which is equal to the detection limit of the direct reading electrochemical sensor. The exposure to carbon monoxide was probably low because exposure only occurred when driving in and out of the tunnel using a diesel powered locomotive. Moreover, the TBM equipment is electrically powered and fresh air is supplied continuously into the tunnel face through the ventilation system. No formaldehyde measurements were taken on the shotcreting operators or TBM workers. These workers were assigned the AM levels of the drill and blast workers $(0.025 \mathrm{ppm})$, because the source of formaldehyde exposure was the same in these groups (mainly diesel exhaust) and the location of the workers was similar (mainly located in the front of the tunnel). The outdoor ambient air level was regarded as an estimate of outdoor workers' exposure to nitrogen dioxide (15 ppb) and carbon monoxide (0.5 ppm) (personal communication from the Norwegian Institute for Air Research, Kjeller, Norway).

The exposures of engineers and foremen who were not measured were calculated by comparing the amount of time that these workers were in the tunnels to that of the drill and blast workers. The engineers were therefore assigned levels of 0 or $1 / 10$ of the AM exposure levels of the drill and blast workers, whereas the foremen were assigned levels of $0,1 / 10$, or $1 / 5$ of the AM exposure levels of the drill and blast workers. Cumulative exposure was adjusted for sick leave, except for engineers, because this information was only recently recorded.

There was no information on the use of respirators. However, in the exposure study ${ }^{9}$ we observed that respirators generally were not worn by the workers during the work shift, except for shotcreting operators and TBM workers, both of whom occasionally wore dust masks. No adjustments were made, therefore, for respiratory use.

\section{Lung function}

Spirometry

Each worker had regular health check ups, at least once every 3-5 years, which included spirometric measurements. Additional check ups were performed on workers deemed by the company as working in jobs with excessive exposure (that is, drill and blast workers and shotcreting operators). 


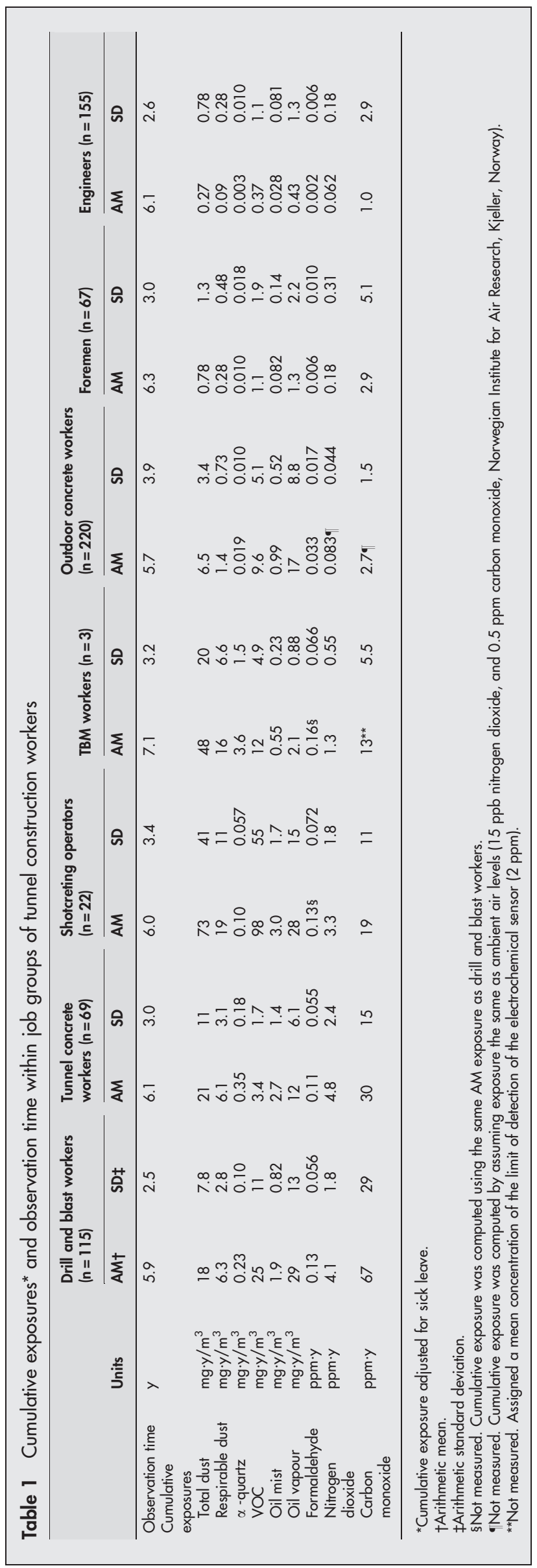

Thus, the workers in this study had an unequal number of check ups and the time periods between the lung function tests differed.

Four nurses and the company physician received special training to calibrate the equipment and carry out the examinations. Spirometric measurements were performed using two bellow spirometers (Vitalograph $S$ with PFT2 PLUS printer, Buckingham, UK). Calibrations and the measurements were performed in accordance with the guidelines recommended by the American Thoracic Society. ${ }^{13}$ Recorded variables were forced vital capacity (FVC) and forced expiratory volume in one second $\left(\mathrm{FEV}_{1}\right)$. The lung function variables were expressed in absolute values and as percentages of the predicted values, using the reference values of the European Coal and Steel Community (ECSC). ${ }^{14}$ No good reference data from Norway are available so the percentage predicted values may be biased. However, the changes in lung function are not likely to be affected.

\section{Data analysis}

Measured exposure values were used without further adjustments for the time sampled because they were regarded as representative of the work shift. The exposure data were found to be best described by log-normal distributions and were therefore log transformed for statistical analysis.

In order to evaluate whether the workers within the job groups were uniformly exposed to dust and gases, the within $\left(G D_{W W}\right)$ and between worker $\left(G S_{B W}\right)$ geometric standard deviations were estimated. Variance components were estimated by random effects ANOVA using the restricted maximum likelihood (REML) algorithm because the workers had an unequal number of repeated measurements. To evaluate exposure contrasts between the job groups, the within group $\left(\mathrm{GSD}_{\mathrm{WG}}\right)$, between group $\left(\mathrm{GSD}_{\mathrm{BG}}\right)$, and between worker $\left(\mathrm{GSD}_{\mathrm{BW}}\right)$ standard deviations were estimated by the mixed effects models with job group as fixed effect and subject as random effect ${ }^{15}$ using REML. The contrast in mean exposure levels between job groups was calculated as described by Kromhout and Heederik: ${ }^{16}$

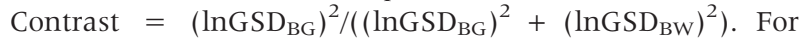
statistical tests a significance level of 0.05 was chosen.

Longitudinal analyses of the lung function data were based on data from the first and last observation of those workers with more than two check ups. The change in lung function ( $\triangle \mathrm{FVC}$ and $\triangle \mathrm{FEV}_{1}$ ) was defined as the difference between lung function at the last observation and the first observation (negative values indicate a decrease in lung function). Individual lung function changes were evaluated by comparing the lung function at first and last observation using paired $t$ tests. The TBM workers were excluded from the final analyses because of their low number $(n=3)$. In addition one engineer, one foreman, one outdoor worker, and one drill and blast worker who had an increase in $\mathrm{FEV}_{1}$ of $1-2$ litres during 2-12 years follow up were also excluded from the final analyses, as these changes may have been due to the subjects having a respiratory infection at the first examination.

Prior to statistical modelling, the correlations between continuous predictor variables were evaluated using Pearson's correlation coefficients. Most cumulative exposures were moderately to strongly correlated (table 2). Exposure to carbon monoxide and total dust were not included in the models as the influence of carbon monoxide on lung function was considered minor and the effect of total dust was better estimated by respirable dust. Therefore only cumulative exposure to respirable dust, $\alpha$-quartz, nitrogen dioxide, and oil vapour were evaluated in models with more than one exposure variable. 
Table 2 Correlation matrix of cumulative exposure variables (Pearson correlation coefficient)

\begin{tabular}{|c|c|c|c|c|c|c|c|c|}
\hline & Respirable dust & $\alpha$-quartz & $\begin{array}{l}\text { Nitrogen } \\
\text { dioxide }\end{array}$ & $\begin{array}{l}\text { Carbon } \\
\text { monoxide }\end{array}$ & Oil mist & Oil vapour & VOC & Formaldehyde \\
\hline $\begin{array}{l}\text { Total dust } \\
\text { Respirable dust } \\
\alpha \text {-quartz } \\
\text { Nitrogen dioxide } \\
\text { Carbon monoxide } \\
\text { Oil mist } \\
\text { Oil vapour } \\
\text { VOC }\end{array}$ & 0.99 & $\begin{array}{l}0.42 \\
0.48\end{array}$ & $\begin{array}{l}0.67 \\
0.75 \\
0.48\end{array}$ & $\begin{array}{l}0.49 \\
0.61 \\
0.40 \\
0.88\end{array}$ & $\begin{array}{l}0.81 \\
0.83 \\
0.41 \\
0.88 \\
0.69\end{array}$ & $\begin{array}{l}0.64 \\
0.68 \\
0.24 \\
0.66 \\
0.76 \\
0.80\end{array}$ & $\begin{array}{l}0.91 \\
0.89 \\
0.15 \\
0.46 \\
0.44 \\
0.62 \\
0.69\end{array}$ & $\begin{array}{l}0.78 \\
0.85 \\
0.55 \\
0.94 \\
0.89 \\
0.93 \\
0.84 \\
0.63\end{array}$ \\
\hline
\end{tabular}

Multiple linear regression models for lung function changes were first developed with inclusion of only one exposure variable adjusted for age and years for non-smokers and ever smokers separately. To evaluate exposure-response trends cumulative exposure concentrations of each agent were categorised in tertiles. The covariate body weight had no significant influence on any of the associations and was therefore excluded from the models.

Multiple linear regression models were constructed with two exposure variables using only significant variables in all possible combinations for non-smokers and ever smokers separately. Separate analyses were then performed on: (1) workers who were included in the Ulvestad study ${ }^{8}$ and those who were not; (2) only blue collar workers; and (3) age groups $(<30$ years and $\geqslant 30$ years $)$.

To assess the fit of the final models the influence of outliers was evaluated and residual plots were studied. Eigenvalues were studied to evaluate collinearity between independent variables. ${ }^{17}$ All data analyses were performed using SYSTAT 10.0 and SPSS 11.0 (SPSS Inc., Chicago, IL, USA).

\section{RESULTS}

The total number of spirometric measurements was 1995, which were performed on 651 workers. Of these, 428 workers had more than two measurements (1549 observations). The mean follow up time between the first and the last check up and the mean number of spirometric measurements was 6.0 years (range 0.4-13.6) and 3 (range 2-7), respectively. Eleven per cent of the workers changed smoking category between observations. Of the 651 workers, 191 were workers from the Ulvestad and colleagues ${ }^{8}$ cohort.

\section{Exposure}

The between worker variability $\left(\mathrm{GSD}_{\mathrm{BW}}=2.0-3.4\right)$ of the exposure measurements was greater than the within worker variability $\left(G S D_{W w}=1.7-2.4\right)$ for total dust, respirable dust, $\alpha$-quartz, and carbon monoxide, whereas the within worker variability $\left(\mathrm{GSD}_{\mathrm{Ww}}=1.8-5.4\right)$ was greater than the between worker variability $\left(\mathrm{GSD}_{\mathrm{BW}}=1.0-2.5\right)$ for the other exposures. After dividing the population into job groups, the between worker variability of all agents was considerably reduced within most job groups compared with the whole population

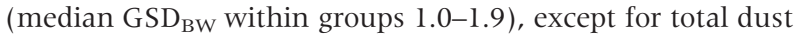
( shotcreters, $\mathrm{GSD}_{\mathrm{BW}}=2.4$ ), $\alpha$-quartz (tunnel concrete workers, $\mathrm{GSD}_{\mathrm{BW}}=4.4$ ), oil vapour (outdoor concrete workers, $\mathrm{GSD}_{\mathrm{BW}}=1.6$ ), volatile organic chemicals (VOCs) (outdoor concrete workers, $\mathrm{GSD}_{\mathrm{BW}}=3.0$ ), and nitrogen dioxide (drill and blast workers, $\mathrm{GSD}_{\mathrm{BW}}=1.4$ ).

The contrast between job groups was compared for each measure of exposure. In general, the highest contrast in mean exposure between groups was obtained for carbon monoxide (1.0), VOC (1.0), oil mist (1.0), respirable dust (0.69), and oil vapour (0.72). The contrast was moderate for total dust (0.46) and $\alpha$-quartz (0.48). There was no contrast between the groups for nitrogen dioxide, thus these tunnel workers may be regarded as homogeneous with regard to nitrogen dioxide exposure. However, the actual contrast between the job groups in the epidemiological analyses is underestimated, because the exposure of two of the low exposed groups (foremen and engineers) was not measured.

Shotcreting operators were exposed to the highest mean cumulative exposures to total dust, respirable dust, VOC, and oil mist during the study period (table 1). The drill and blast workers were the highest exposed to oil vapour and carbon monoxide, the TBM workers were the highest exposed to $\alpha$-quartz and formaldehyde, and the tunnel concrete workers were the highest exposed to nitrogen dioxide. The outdoor concrete workers were exposed to the lowest mean cumulative exposure to all agents compared to the tunnel workers, except for VOC and oil vapour.

\section{Lung function}

Characteristics and lung function at first observation There were no major differences between the seven groups at the start of the survey with respect to age and weight (table 3 ). The proportions of ever smokers were generally higher in the tunnel construction workers compared to the low exposed groups (outdoor concrete workers, foremen, and engineers). For the entire study group, the mean values of FVC and $\mathrm{FEV}_{1}$ at the start of the survey were $104 \%$ and $99 \%$ of predicted, respectively. There were no statistical differences among the groups at the first observation, although all reference groups generally had slightly better predicted $\mathrm{FEV}_{1}$ value than the tunnel workers. However, when the tunnel workers and low exposed groups were separated in two groups the mean difference in percentage of predicted $\mathrm{FEV}_{1}$ between the groups was significant $(p<0.05)$. The individual lung function changes between the first and last observation differed significantly from zero within all job groups $\left(\Delta \mathrm{FEV}_{1} \mathrm{p}<0.01\right.$, and $\left.\Delta \mathrm{FVC} \mathrm{p}<0.01\right)$, except for TBM workers.

\section{Job groups and lung function}

In general, the low exposed workers (engineers, foremen, and outdoor concrete workers) showed no or a minor increase in $\mathrm{FEV}_{1}$ between the first and last observation, whereas the tunnel workers showed a decrease in lung function between observations except for TBM workers (table 4). The pattern was generally consistent for both smoking categories, although most job groups of workers who smoked experienced a greater loss in lung function compared to non-smoking tunnel workers and to the low exposed groups. This can also be observed from the annual change in $\mathrm{FEV}_{1}$ and FVC.

\section{Associations between cumulative exposures and lung function decline}

A decrease in $\mathrm{FEV}_{1}$ was found to be associated with all exposures (table 5). However, cumulative exposures to $\alpha$-quartz, oil vapour, and carbon monoxide in non-smokers, 

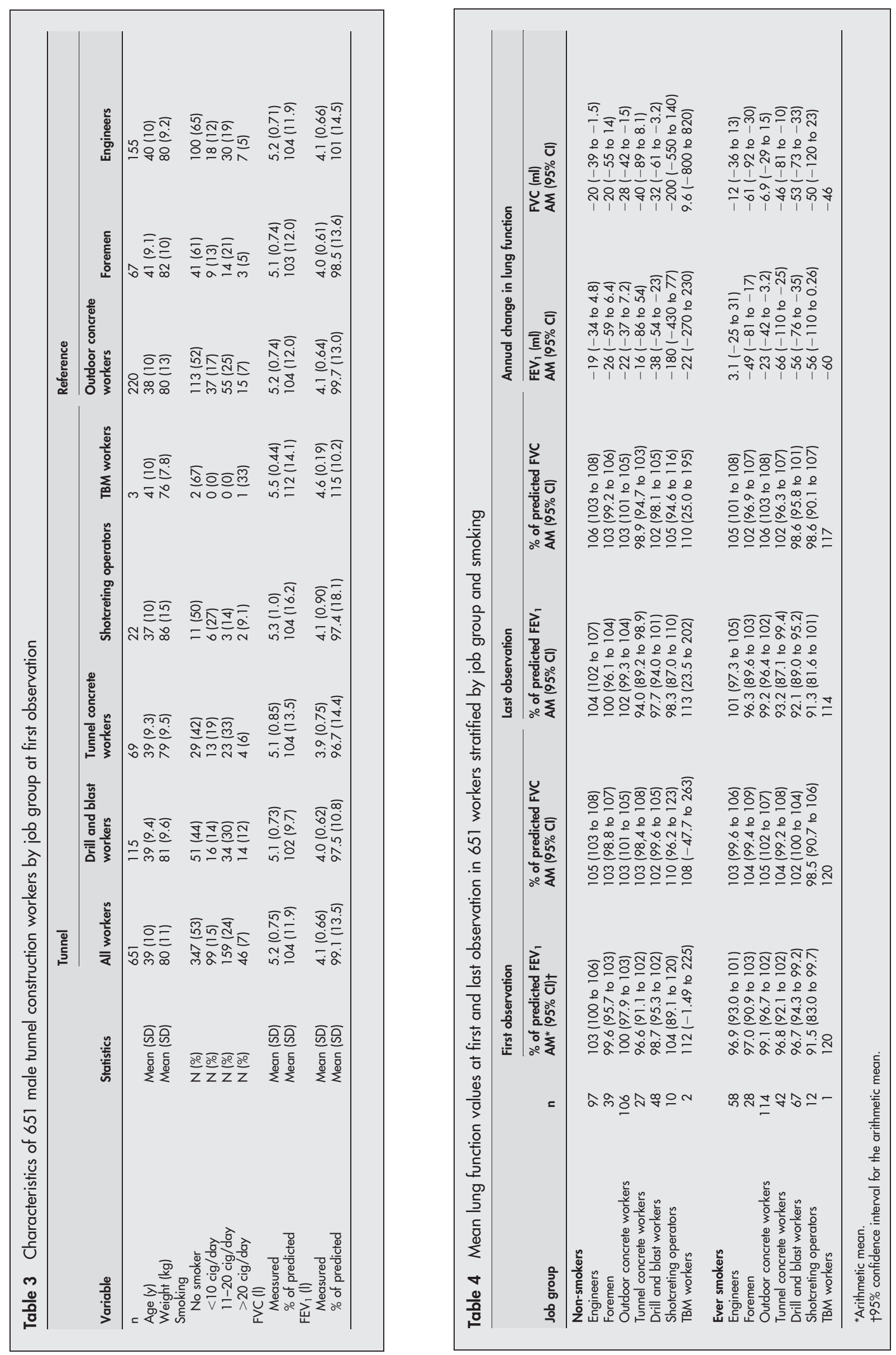

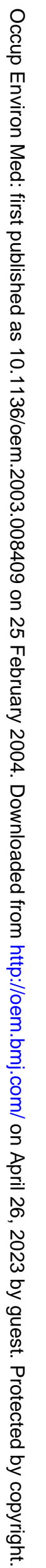


Table 5 Lung function changes in 644 tunnel construction workers* predicted by multiple linear regression models using one exposure variable† adjusted for age and observation time (years) by non-smokers and ever smokers

\begin{tabular}{|c|c|c|c|c|c|c|}
\hline \multirow[b]{2}{*}{ Agent } & \multirow[b]{2}{*}{ Units } & \multicolumn{3}{|c|}{ Regression coefficient } & \multirow{2}{*}{$\begin{array}{l}\text { One year mean } \\
\text { exposures }\end{array}$} & \multirow{2}{*}{$\begin{array}{l}\text { Predicted annual decrease in } \mathrm{FEV}_{1} \\
(\mathrm{ml}) \text { for mean exposures }\end{array}$} \\
\hline & & b & SE & $95 \% \mathrm{Cl}$ & & \\
\hline \multicolumn{7}{|l|}{ Non-smokers } \\
\hline Total dust & $\mathrm{mg} \cdot \mathrm{y} / \mathrm{m}^{3}$ & -4.0 & 1.3 & -6.5 to -1.4 & 1.7 & -6.6 \\
\hline Respirable dust & $\mathrm{mg} \cdot \mathrm{y} / \mathrm{m}^{3}$ & -16 & 4.5 & -24 to -6.8 & 0.48 & -7.7 \\
\hline$\alpha$-quartz & $\mathrm{mg} \cdot \mathrm{y} / \mathrm{m}^{3}$ & -610 & 150 & -890 to 320 & 0.016 & -10 \\
\hline VOC & $\mathrm{mg} \cdot \mathrm{y} / \mathrm{m}^{3}$ & -2.0 & 0.99 & -3.9 to -0.005 & 1.9 & -3.8 \\
\hline Oil mist & $\mathrm{mg} \cdot \mathrm{y} / \mathrm{m}^{3}$ & -57 & 18 & -93 to -21 & 0.17 & -9.7 \\
\hline Oil vapour & $\mathrm{mg} \cdot \mathrm{y} / \mathrm{m}^{3}$ & -1.9 & 1.6 & -5.0 to 1.2 & 2.1 & -4.0 \\
\hline Formaldehyde & $\mathrm{ppm} \cdot \mathrm{y}$ & -1200 & 340 & -1900 to -520 & 0.008 & -9.6 \\
\hline Nitrogen dioxide & $\mathrm{ppm} \cdot \mathrm{y}$ & -39 & 9.0 & -57 to -21 & 0.21 & -8.2 \\
\hline Carbon monoxide & $\mathrm{ppm} \cdot \mathrm{y}$ & -2.3 & 0.70 & -3.7 to 0.91 & 2.7 & -6.1 \\
\hline \multicolumn{7}{|l|}{ Ever smokers } \\
\hline Total dust & $\mathrm{mg} \cdot \mathrm{y} / \mathrm{m}^{3}$ & -2.0 & 1.1 & -4.2 to 0.23 & 2.2 & -4.3 \\
\hline Respirable dust & $\mathrm{mg} \cdot \mathrm{y} / \mathrm{m}^{3}$ & -9.3 & 4.0 & -17 to -1.5 & 0.63 & -5.9 \\
\hline$\alpha$-quartz & $\mathrm{mg} \cdot \mathrm{y} / \mathrm{m}^{3}$ & -590 & 130 & -840 to -340 & 0.02 & -12 \\
\hline VOC & $\mathrm{mg} \cdot \mathrm{y} / \mathrm{m}^{3}$ & -0.80 & 0.84 & -2.5 to 0.86 & 2.4 & -1.9 \\
\hline Oil mist & $\mathrm{mg} \cdot \mathrm{y} / \mathrm{m}^{3}$ & -75 & 17 & -110 to -41 & 0.23 & -17 \\
\hline Oil vapour & $\mathrm{mg} \cdot \mathrm{y} / \mathrm{m}^{3}$ & -7.4 & 1.6 & -11 to -4.1 & 2.7 & -20 \\
\hline Formaldehyde & $\mathrm{ppm} \cdot \mathrm{y}$ & -1600 & 330 & -2200 to -970 & 0.01 & -16 \\
\hline Nitrogen dioxide & $\mathrm{ppm} \cdot \mathrm{y}$ & -38 & 8.2 & -54 to -22 & 0.32 & -12 \\
\hline Carbon monoxide & $\mathrm{ppm} \cdot \mathrm{y}$ & -3.3 & 0.67 & -4.6 to -2.0 & 3.6 & -12 \\
\hline
\end{tabular}

*Three TBM workers and one engineer, one foreman, and one outdoor worker were excluded from the final analyses.

†Cumulative exposure adjusted for sick leave.

and total dust and VOC in ever smokers were not significant. The magnitude of the effect ( $\left.b^{\prime} s\right)$ is only informative if one takes into account an expected exposure level of the agent. For instance, the size of the coefficient for respirable dust for a non-smoker was $-16 \mathrm{mg} \cdot \mathrm{y} / \mathrm{m}^{3}$. This coefficient is equivalent to an excess annual loss of $7.7 \mathrm{ml}$ in $\mathrm{FEV}_{1}$ when exposed to a concentration of $0.48 \mathrm{mg} / \mathrm{m}^{3}$ during a year. The decrease in $\mathrm{FEV}_{1}$ in ever smokers was significantly associated with the medium and highest exposure categories for all agents (not shown). For non-smokers similar trends were observed but these were weaker and not significant (not shown).

After including all exposures, cumulative exposure to nitrogen dioxide showed the strongest association of all agents, with a decrease in $\mathrm{FEV}_{1}$ in both non-smokers and ever smokers (table 6). Inclusion of other exposure variables did not improve the model significantly. The effect of nitrogen dioxide exposure was almost the same in both groups $(-38 ;-39 \mathrm{ppm} \cdot \mathrm{y})$. The effect of observation time was much less in ever smokers compared to non-smokers, but the average change in lung function in a worker 40 years of age over the mean observation time ( 6 years) was similar in both groups $(-143 v-127 \mathrm{ml}$, respectively). The reduction in FVC during the study period was associated with cumulative exposure to $\alpha$-quartz in both non-smokers and ever smokers (not shown, $\mathrm{p}<0.001$ ). The effect of $\alpha$-quartz exposure was similar in both groups $\left(-0.7 ;-0.5 \mu \mathrm{g} \cdot \mathrm{y} / \mathrm{m}^{3}\right)$.

Separate analyses on only the workers that were included in the Ulvestad and colleagues ${ }^{8}$ study and those who were not showed that the estimated effect of nitrogen dioxide exposure on $\triangle \mathrm{FEV}_{1}$ was similar within these workers (not shown). Restricting the analyses to those who had ever worked in the production areas by excluding the engineers did not change the results, nor did analysing for the effect of age.

\section{DISCUSSION}

In this study data from routinely performed medical examinations in one of Norway's major construction companies were used to relate lung function to employment in tunnel construction work. Loss of $\mathrm{FEV}_{1}$ was related to cumulative exposure to many agents, but it was strongest for nitrogen dioxide in both non-smokers and ever smokers.

The results of this study extend the findings of Ulvestad and colleagues ${ }^{8}$ who found that respirable dust and $\alpha$-quartz

Table 6 Multiple linear regression model for $\Delta \mathrm{FEV}_{1}(\mathrm{ml})$ during the follow up period for 644 tunnel construction workers* by non-smokers and ever smokers

\begin{tabular}{|c|c|c|c|}
\hline \multirow[b]{2}{*}{ Covariables } & \multicolumn{3}{|c|}{$\Delta \mathrm{FEV}_{1}(\mathrm{ml})$} \\
\hline & b & SE & p value \\
\hline \multicolumn{4}{|l|}{ Never smokers $\left(R_{\text {adjusted }}^{2}=0.09\right)$} \\
\hline Constant & 67 & 84 & 0.4 \\
\hline Observation time (y) & -20 & 7.0 & $<0.01$ \\
\hline Age $(y)$ & -1.8 & 1.7 & \\
\hline Cumulative exposure to nitrogen dioxide $(\mathrm{ppm} \cdot \mathrm{y})$ & -39 & 9.0 & $<0.001$ \\
\hline \multicolumn{4}{|l|}{ Ever smokers $\left(R_{\text {adjusted }}^{2}=0.08\right)$} \\
\hline Constant & 30 & 98 & 0.8 \\
\hline Observation time (y) & -0.73 & 7.3 & 0.9 \\
\hline Age $(y)$ & -4.2 & 2.2 & 0.06 \\
\hline Cumulative exposure to nitrogen dioxide $\nmid(\mathrm{ppm} \cdot \mathrm{y})$ & -38 & 8.2 & $<0.001$ \\
\hline
\end{tabular}

*Three TBM workers and one engineer, one foreman, and one outdoor worker were excluded from the final analyses.

†Cumulative exposure is adjusted for sick leave. 
were major risk factors for lung function decrease. Because of the high correlation between nitrogen dioxide and respirable dust, the Ulvestad study was not able to distinguish between these two exposures. The differences between these two studies were primarily the larger number of job groups available in this study, and the better information on smoking habits in the Ulvestad study.

\section{Exposure}

The exposure classification was generally satisfactory as few workers needed to be reassigned to other jobs. However, some workers may have been misclassified as temporary job assignments and support work were not defined in this company's files, but were instead identified as drill and blast workers. The support workers were exposed to levels similar to the drill and blast workers, ${ }^{9}$ and therefore the classification of support workers as drill and blast workers is not expected to introduce severe misclassification.

The job groups reflected differences in exposures; we therefore expected that differences in annual change in lung function would be reflected in differences between job groups. This was supported by the findings. The high exposure job groups showed larger decreases in lung function than the low exposure groups. However, job group by itself does not take into account the length of the observation period of each worker and differences in exposure levels between agents within and between groups. Quantitative estimates and duration of work were expressed together as cumulative exposures to study the association between exposure and lung function decrease.

After grouping of workers into job groups, the between worker component of variability was considerably reduced in most groups compared to the whole population, suggesting that the use of these job groups was reasonable. The contrast in exposure levels among job groups was moderate to high for all agents when only the measured groups were considered (the various tunnel worker groups and outdoor concrete workers), except for nitrogen dioxide where no between worker variance was observed. However, cumulative exposure levels differed between workers as workers had different observation times. Engineers and foremen were in the low exposed groups with respect to all agents, and their mean cumulative exposures were much lower than the other groups. The contrast between job groups with respect to cumulative exposures was therefore larger than when using only the measured groups.

Optimal grouping of workers in epidemiological studies should be based on not only job groups, but also on information on other exposure determinants. ${ }^{18}$ Information on these other determinants was not available for this data set.

We did not have any information as to whether participants had left the company temporarily between health check ups. This may have lead to an overestimation of exposure. However, in our experience, skilled construction workers migrate between employers and not across crafts. Therefore we do not think that absence between health check ups interfered with the results substantially. There may also have been misclassifications of workers due to temporary work assignments, but this should have minimal effect on the findings due to short duration of these periods.

\section{Lung function}

The annual decrease in $\mathrm{FEV}_{1}$ predicted by the final model for non-exposed, non-smoking individuals was estimated to be $21 \mathrm{ml}$ for six years, which is similar to the results of the Ulvestad study $(25 \mathrm{ml})$. The annual decrease in $\mathrm{FEV}_{1}$ was similar for non-exposed ever smokers $(24 \mathrm{ml})$, which is probably due to the availability of only crude information on smoking habits. The excess annual decline in $\mathrm{FEV}_{1}$ in nonsmoking tunnel construction workers was estimated to be $26 \mathrm{ml}$ in drill and blast workers, $31 \mathrm{ml}$ in tunnel concrete workers, and $21 \mathrm{ml}$ in shotcreters. The estimates of the effect of exposure in drill and blast workers are similar in the Ulvestad study and this study ( $25 \mathrm{ml} v 26 \mathrm{ml}$, respectively), but somewhat different for shotcreters $(38 \mathrm{ml} v 21 \mathrm{ml})$. The difference was not significant, possibly due to the small number of shotcreting operators.

A bias could have arisen if the engineers used as a reference group were different in terms of respiratory health and lifestyle from both the other reference groups (outdoor workers and foremen) and the tunnel workers. The engineers were more highly educated and were mainly office people, and it could therefore be expected that they had different lifestyles than the construction workers. However, the most important lifestyle factor (smoking) was accounted for by the models, and exclusion of the engineers from the analyses did not alter the findings.

Information on smoking habits was obtained from self reported information in the company questionnaire. We had no reliable information on smoking habits prior to the study period, and because it was not possible to calculate packyears of smoking we chose to stratify the workers into two smoking categories (non- versus ever smokers). The analyses on ever smokers may therefore be confounded by different tobacco consumption between workers and within workers. Smoking was more common among tunnel construction workers and outdoor concrete workers compared to engineers (53\% v 37\%).

The health service team carrying out the health check ups examined all workers who were present. They did not have any information on exposures. Therefore we have no reason to believe that the workers covered are non-representative of the total workforce. However, some workers may have left the company during the study and therefore were not subject to follow up. This turnover may lead to an underestimation of the exposure-response estimates if the reason for leaving work was related to respiratory illness. The latter have been observed by Soutar and Hurley ${ }^{19}$ who found that ex-miners who had left work before compulsory retirement at age 65 had worse lung function than miners on average, suggesting that some workers may have left the industry due to health problems.

We found a decrease in FVC in both non-smokers and ever smokers which was related to cumulative exposure to $\alpha$-quartz. This finding was supported by a previous crosssectional study of this population ${ }^{1}$ in which a reduction in FVC was related to years employed in the tunnel construction industry. However, after eight years follow up of this cohort, Ulvestad and colleagues were not able to detect any long term effect on level of FVC, and none of the workers studied had radiographic signs of pneumoconiosis when examined in 1991 and $1999 .{ }^{8}$ The effect of $\alpha$-quartz exposure on FVC in tunnel workers therefore remains unclear.

Nitrogen dioxide is generated from both diesel powered machines and blasting during tunnel construction. The Norwegian occupational exposure limit of nitrogen dioxide is $2 \mathrm{ppm}$, which is a ceiling limit. ${ }^{20}$ We found that a decrease in $\mathrm{FEV}_{1}$ was associated with several agents when only one agent was introduced in the models. When several agents were introduced in the models nitrogen dioxide showed the strongest association of all agents. However, exposures such as respirable dust, $\alpha$-quartz, oil mist, oil vapour, VOC, and formaldehyde were all moderately to strongly correlated to nitrogen dioxide and were considered for their possible contribution to the observed decrease in $\mathrm{FEV}_{1}$. Several of the measured agents do, however, not appear to be a likely cause of the observed lung function decrease because of low levels 
(that is, oil mist, oil vapour, VOC, and formaldehyde). Thus, from this study nitrogen dioxide, respirable dust, and $\alpha$-quartz are the most likely candidates for causing the observed lung function decrease. In a previous study drill and blast workers exposed to peak exposures of nitrogen dioxide $(>10 \mathrm{ppm})$ showed temporary lung function reduction. ${ }^{3}$ These results support the role for nitrogen dioxide if short term lung function decrease is an indicator of long term lung function changes. The effect of nitrogen dioxide and diesel exhaust has also been studied in miners, ${ }^{21}{ }^{22}$ who are exposed to the same sources of nitrogen dioxide as tunnel construction workers. Neither of these studies has found a relation between nitrogen dioxide exposure and lung function decrease. This may be due to the lower levels of nitrogen dioxide observed in these studies $(0.02-0.1 \mathrm{ppm})$ than in the present study $(0.02-0.8 \mathrm{ppm})$. Interestingly, two other studies have found effects of blasting fumes on lung function in coal miners. ${ }^{23}{ }^{24}$ Exposure to blasting fumes suggests higher concentrations of nitrogen dioxide than during mining when no blasting is performed. A decline in $\mathrm{FEV}_{1}$ has been found after exposure to $1.5 \mathrm{ppm}$ nitrogen dioxide for three hours in human challenge studies, ${ }^{25}$ and increases in airway resistance have been reported at concentrations of 5-8 ppm nitrogen dioxide over both short ( $5 \mathrm{~min}$ ) and longer ( $1-2 \mathrm{~h}$ ) exposures. ${ }^{26}$ This adds to the evidence that nitrogen dioxide seems to be an important risk factor for lung function decrease.

Despite our finding of the association between lung function decrease with nitrogen dioxide exposure, respirable dust and $\alpha$-quartz ${ }^{27}$ may also contribute to the observed effects. As the exposure levels of these agents were moderately correlated to nitrogen dioxide they may have contributed to the association between nitrogen dioxide and decrease in $\mathrm{FEV}_{1}$. Risk management should therefore focus on these agents as well.

\section{Conclusion}

Cumulative exposure to nitrogen dioxide appears to be a major risk factor for lung function decrease in tunnel construction workers although other agents may contribute to the observed effect. Contact with blasting fumes should be avoided, diesel exhaust emission should be reduced, and respiratory devices should be used to protect the workers against dust and nitrogen dioxide exposure.

\section{ACKNOWLEDGEMENTS}

We thank the construction workers for participating in the study, and for discussions with dr. med. Vidar S $\phi$ yseth (Akershus University Hospital) and dr.scient. Arild Vold (Institute of Transport Economics, Norway) on the statistical methods used in this work. We also appreciate comments on the manuscript from Roel Vermeulen, PhD (National Cancer Institute, USA). The project received financial support from the Working Environment Fund of the Confederation of Norwegian Business and Industry.
Authors' affiliations
B Bakke, W Eduard, National Institute of Occupational Health, Oslo, Norway
B Ulvestad, Cancer Registry of Norway, Oslo, Norway

P Stewart, Division of Cancer Etiology and Genetics, National Cancer Institute, Rockville, USA

\section{REFERENCES}

1 Ulvestad B, Bakke B, Melbostad E, et al. Increased risk of obstructive pulmonary disease in tunnel workers. Thorax 2000;55:277-82.

2 Ulvestad B, Lund MB, Bakke B, et al. Gas and dust exposure in underground construction is associated with signs of airway inflammation. Eur Respir J 2001; 17:416-21.

3 Bakke B, Ulvestad B, Stewart $P$, et al. Effects of blasting fumes on exposure and short-term lung function changes in tunnel construction workers. Scand J Work Environ Health 2001 ; 27:250-7.

4 Ulfvarson U, Alexandersson R, Dahlquist $M$, et al. Pulmonary function in workers exposed to diesel exhaust: the effect of control measures. Am J Ind Med 1991; 19:283-9.

5 World Health Organisation (WHO). Nitrogen dioxide, 2nd edn. Environmental Health Criteria, no.188. Geneva: WHO, 1997.

6 Vallyathan V, Castranova V, Pack D, et al. Freshly fractured quartz inhalation leads to enhanced lung injury and inflammation. Potential role of free radicals. Am J Respir Crit Care Med 1995; 152:1003-9.

7 Massin N, Bohadana $A B$, Wild $P$, et al. Airway responsiveness, respiratory symptoms, and exposures to soluble oil mist in mechanical workers. Occup Environ Med 1996:53:748-52.

8 Ulvestad B, Bakke B, Eduard W, et al. Cumulative exposure to dust causes accelerated decline in lung function in tunnel workers. Occup Environ Med 2001;58:663-9.

9 Bakke B, Stewart P, Ulvestad B, et al. Dust and gas exposure in tunnel construction work. AlHAJ 2001;62:457-65.

10 Bakke B, Stewart P, Eduard W. Determinants of dust exposure in tunnel construction work. Appl Occup Environ Hyg 2002;17:783-96.

11 Norwegian Labor Inspection Authority. Norwegian regulations on machines. Publication no. 522. Oslo, Norway: Tiden Norsk Forlag AS, 1994.

12 Rappaport SM. Selection of measures of exposure for epidemiological studies. Appl Occup Environ Hyg 1991;6:448-57.

13 American Thoracic Society. Standardisation of spirometry-1988 update. Am Rev Respir Dis 1997;136:1285-98.

14 Quanjer PH, Tammeling GJ, Cotes JE, et al. Lung volumes and forced ventilat-ory flows. Eur Respir J 1993;6:5-40.

15 Peretz C, Goren A, Smid T, et al. Application of mixed-effects models for exposure assessment. Ann Occup Hyg 2002;46:69-77.

16 Kromhout H, Heederik D. Occupational epidemiology in the rubber industry: implications of exposure variability. Am J Ind Med 1995;27:171-85.

17 Kleinbaum DG, Kupper LL, Muller KE, et al. Applied regression analysis and multivariable methods, 3rd edn. Boston, USA: PWS-KENT Publishing Company, 1998.

18 Tielemans E, Kupper LL, Kromhout H, et al. Individual-based and group-based occupational exposure assessment: some equations to evaluate different strategies. Ann Occup Hyg 1998;42:115-19.

19 Soutar CA, Hurley JF. Relation between dust exposure and lung function in miners and ex-miners. Br J Ind Med 1986;43:307-20.

20 Norwegian Labor Inspection Authority. Norwegian list of occupational exposure limits. Publication no. 361. Oslo, Norway: Tiden Norsk Forlag AS, 1996.

21 Atffield MD, Trabant GD, Wheeler RW. Exposure to diesel fumes and dust at six potash mines. Ann Occup Hyg 1982;26:817-31.

22 Robertson A, Dodgson J, Collings $\mathrm{P}$, et al. Exposure to oxides of nitrogen: respiratory symptoms and lung function in British coalminers. Br J Ind Med 1984;41:214-19.

23 Kennedy MC. Nitrous fumes and coal-miners with emphysema. Ann Occup Hyg 1972;15:285-301.

24 Wang ML, Petsonk EL, Beeckman LA, et al. Clinically important $\mathrm{FEV}_{1}$ declines among coal miners: an exploration of previously unrecognised determinants. Occup Environ Med 1999;56:837-44.

25 Frampton MW, Morrow PE, Cox C, et al. Effects of nitrogen dioxide exposure on pulmonary function and airway reactivity in normal humans. Am Rev Respir Dis 1991;143:522-7.

26 Nieding VG, Wagner HM, Krekeler $\mathrm{H}$, et al. Controlled studies of human exposure to single and combined action of $\mathrm{NO}_{2}, \mathrm{O}_{3}$ and $\mathrm{SO}_{2}$. Int Arch Occup Environ Health 1979:43:195-210.

27 Humerfelt S, Eide GE, Gulsvik A. Association of years of occupational quartz exposure with spirometric airflow limitation in Norwegian men aged 30-46 years. Thorax 1998;53:649-55. 